\title{
Correction to: Neuron-specific biomarkers predict hypo- and hyperalgesia in individuals with diabetic peripheral neuropathy
}

\author{
Jakob Morgenstern ${ }^{1}$ - Jan B. Groener ${ }^{1,2,3}$. Johann M. E. Jende ${ }^{4}$. Felix T. Kurz ${ }^{4}$ Alexander Strom ${ }^{2,5}$. Jens Göpfert ${ }^{6}$. \\ Zoltan Kender $^{1,2}$ - Maxime Le Marois ${ }^{1} \cdot$ Maik Brune $^{1} \cdot$ Rohini Kuner $^{7} \cdot$ Stephan Herzig $^{2,8} \cdot$ Michael Roden $^{2,5,9}$. \\ Dan Ziegler ${ }^{2,5,9} \cdot$ Martin Bendszus $^{4} \cdot$ Julia Szendroedi $^{1,2} \cdot$ Peter Nawroth $^{1,2,8} \cdot$ Stefan Kopf ${ }^{1,2} \cdot$ Thomas Fleming $^{1,2}$
}

Published online: 11 October 2021

๑) Springer-Verlag GmbH Germany, part of Springer Nature 2021

\section{Correction to: Diabetologia https://doi.org/10.1007/s00125-021-05557-6}

The authors regret that funding details for M. Le Marois were omitted. The original article has been corrected.

Publisher's note Springer Nature remains neutral with regard to jurisdictional claims in published maps and institutional affiliations.

The original article can be found online at https://doi.org/10.1007/ s00125-021-05557-6.

Jakob Morgenstern

jakob.morgenstern@med.uni-heidelberg.de

1 Internal Medicine I and Clinical Chemistry, University Hospital of Heidelberg, Heidelberg, Germany

2 German Center for Diabetes Research (DZD), Neuherberg, Germany

3 Medicover München Neuroendokrinologie, Munich, Germany

4 Department of Neuroradiology, University Hospital of Heidelberg, Heidelberg, Germany

5 Institute for Clinical Diabetology, German Diabetes Center, Leibniz Center for Diabetes Research at Heinrich Heine University Düsseldorf, Düsseldorf, Germany
6 NMI Natural and Medical Sciences Institute at the University of Tübingen, Reutlingen, Germany

7 Department of Molecular Pharmacology, Institute of Pharmacology, Heidelberg University, Heidelberg, Germany

8 Institute for Diabetes and Cancer at Helmholtz Zentrum Munich, Neuherberg, Germany

9 Division of Endocrinology and Diabetology, Medical Faculty, Heinrich Heine University, Düsseldorf, Germany 